Appl. Ent. Zool. 14 (4) : 453-458 (1979)

\title{
The Role of Intracellular Yeastlike Symbiotes in the Development of Laodelphax striatellus (Homoptera: Delphacidae)
}

\author{
Hiroaki NodA ${ }^{1}$ and Tetsuo SAIto \\ Laboratory of Applied Entomology and Nematology, Faculty of Agriculture, \\ Nagoya University, Chikusa-ku, Nagoya 464, Japan
}

(Received May 22, 1979)

\begin{abstract}
The intracellular yeastlike symbiotes in Laodelphax striatellus are destroyed by heat treatment (at $35^{\circ} \mathrm{C}$ for the first 3 days of the nymph). The heat treatment shows a deleterious effect on the adult moult; a number of the insects fail to emerge. The administration of cholesterol to the heat-treated insects largely promoted the adult moult. $\beta$-Sitosterol also had an effect on the recovery of the deleterious effect. The heat-treated 5 th-instar nymphs fairly moulted by application of ecdysterone. The deleterious effect seems to come from the collapse of the yeastlike symbiotes through steroid metabolism of the insect. The yeastlike symbiotes appear to play an important role in supplying sufficient sterol for the development of $L$. striatellus.
\end{abstract}

\section{INTRODUGTION}

The smaller brown planthopper, Laodelphax striatellus, normally harbours yeastlike symbiotes and prokaryotic microorganisms in the fat body (NAsU, 1963; NoDA, 1977; NodA and SAIto, 1979). Heat treatment (exposure to high temperature, $35^{\circ} \mathrm{C}$, for the first 3 days after hatching) reduces the number of yeastlike symbiotes (NodA and SArto, 1979). Some 5th-instar nymphs die in the process of ecdysis, and some do not moult. These heat-treated insects do not normally deposit adult cuticle. Sterol analyses show that the yeastlike symbiotes play an important role as a sterol source for the planthopper: the symbiotes supply their host insect with 24-methylenecholesterol (NoDA et al., 1979).

In the present paper, sterols and ecdysterone were administered to the heat-treated insects to investigate whether these nutrients or hormone are able to recover the defect of adult moult caused by the heat treatment. The role of the yeastlike symbiotes in L. striatellus is also discussed as contributor to the host development through steroid metabolism.

\section{MATERIALS AND METHODS}

Sterol administration. Sterols used were cholesterol and $\beta$-sitosterol ( $24 \alpha$-ethylcholest-5-en-3 $\beta$-ol) (Katayama Chemical Co., Ltd.). $\beta$-Sitosterol used here consisted

1 Present address: Shimane Agricultural Experiment Station, 2440 Ashiwata, Izumo, Shimane 693, Japan. 


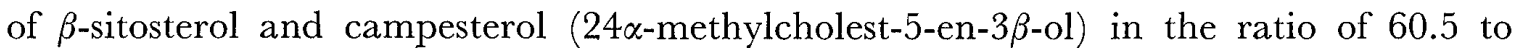
39.5 , respectively, on the basis of gas liquid chromatography. The sterols were given to insects through rice sheath in a glass tube (about $103 \mathrm{~mm}$ in length, $14 \mathrm{~mm}$ in diameter). The insects were allowed to suck the rice sheath the lower end of which was dipped into the water containing the sterol. The sterols were stirred alone or emulsified in $0.1 \%$ of Tween 85 (Polyoxyethylene sorbitan trioleate, Katayama Chemical Co., Ltd.) at the concentration of $0.1 \%$.

Laodelphax striatellus (Fallén) was stock-cultured on rice seedlings at $25^{\circ} \mathrm{C}$ under $16 \mathrm{hr}$ daily illumination. The newly hatched nymphs were moved into the glass tube, exposed to $35^{\circ} \mathrm{G}$ for 3 days (heat treatment), and transferred to $25^{\circ} \mathrm{G}$ (NoDA and SAIto, 1979). The rice sheaths were changed every one or two days.

Ecdysterone application. Ecdysterone $\left(\mathrm{C}_{27} \mathrm{H}_{44} \mathrm{O}_{7}\right.$, Rohto Pharmaceutical Co., Ltd.) dissolved in methanol was topically applied to the heat-treated 5th-instar nymphs of 19 days old after hatching by means of a microsyringe. About $0.125 \mu l$ each, the ecdysterone doses varying from $1 \mu \mathrm{g}$ to $10^{-5} \mu \mathrm{g}$, was spread on the dorsal part of the insects. The treated insects were reared on a rice sheath for 4 days.

\section{RESULTS}

\section{Administration of sterols to the heat-treated insects}

Fig. 1 shows the survival rate and the rate of emergence of the heat-treated and non-heat-treated insects to which sterol was administered with Tween 85 . The normal insects became adults within 22 days after hatching. In the heat-treated insects which did not take sterol, only $6.7 \%$ emerged and the others were dead by the 38th day. When cholesterol was given, $61.6 \%$ of the heat-treated insects became adults. However they took much more time to emerge than the normal insects. $\beta$-Sitosterol promoted the rate of emergence to $15.2 \%$ and was not as effective as cholesterol.

Similar results were also obtained by rearing without Tween 85 (Fig. 2). The

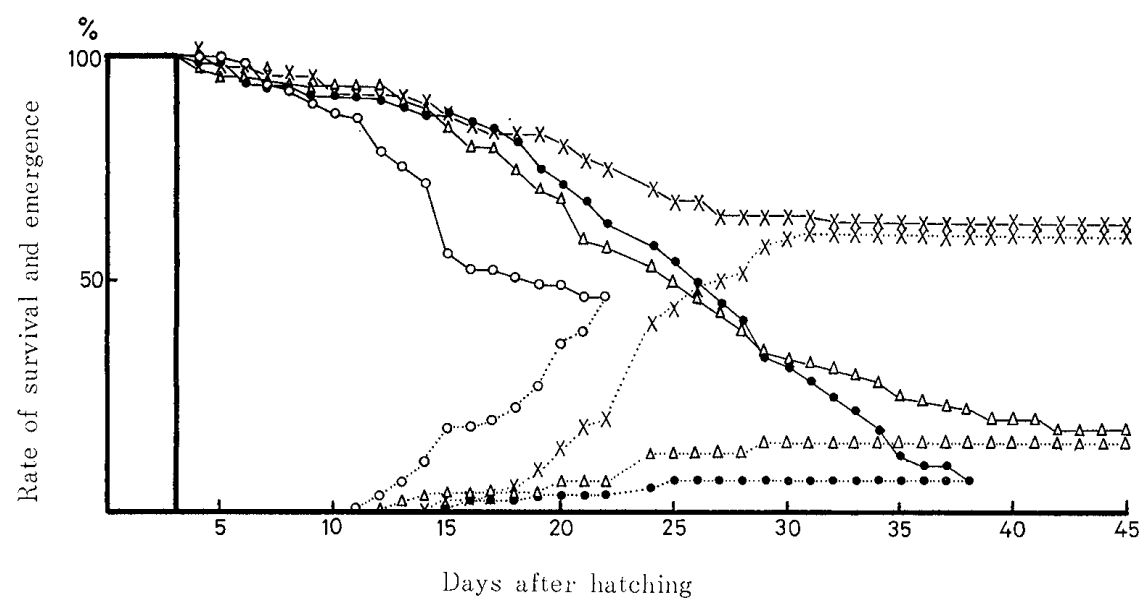

Fig. 1. The rate of survival and emergence of the heat-treated insects to which sterols are administered with Tween 85 . - - survival rate; ....., the rate of emergence; $\bigcirc$, normal temperature $25^{\circ} \mathrm{C}$;, $35^{\circ} \mathrm{C}$ for the first 3 days after hatching and $25^{\circ} \mathrm{C}$ for the rest of the life (heat treatment); $\times$, heat treatment and cholesterol administration; $\triangle$, heat treatment and $\beta$-sitosterol (including campesterol) administration. 


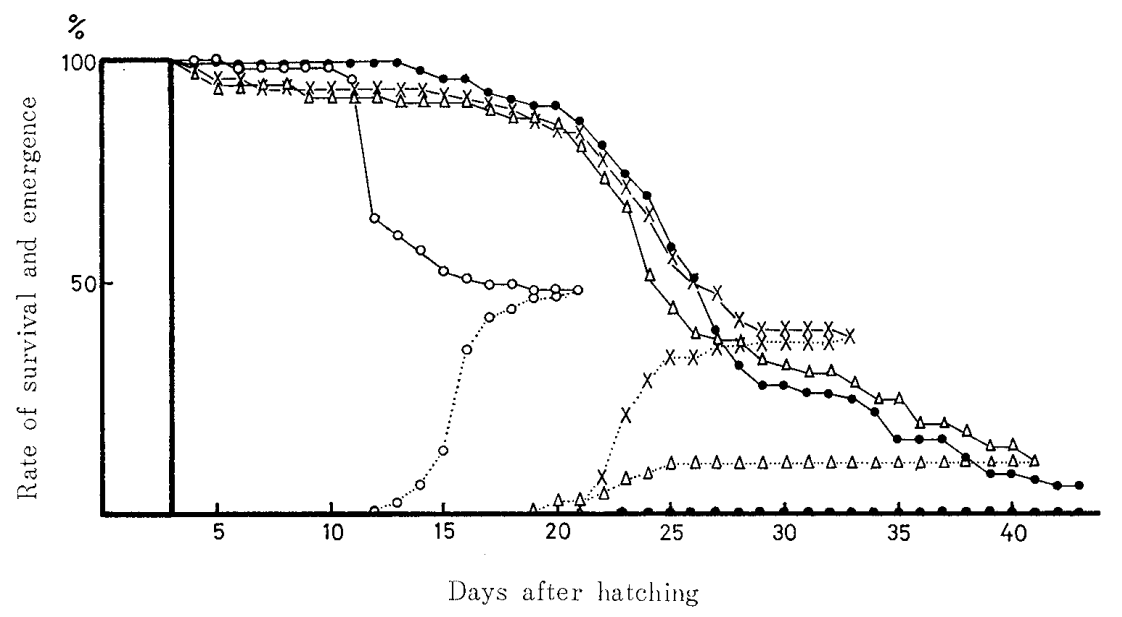

Fig. 2. The rate of survival and emergence of the heat-treated insects to which sterols are administered. Signs are shown in the footnote of Fig. 1.

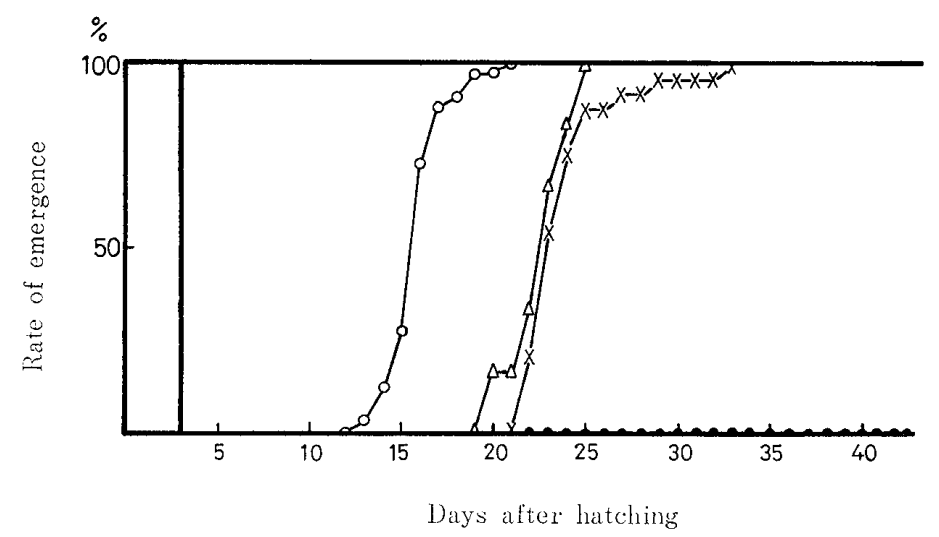

Fig. 3. Growth curve of adult emergence. The cumulative number of adults each day are divided by the total number of adults. Figures are taken from Fig. 2.

heat-treated insects did not emerge at all even the 43rd day after hatching. $10.7 \%$ of the insects which ingested $\beta$-sitosterol moulted into adults. Cholesterol promoted the rate of emergence to $37.1 \%$.

The heat-treated 5th-instar nymphs to which cholesterol was administered were fixed and their paraffin sections were examined under microscope (NoDA, 1977). Since the yeastlike symbiotes remained few, the sterol administration after the heat treatment did not recover the symbiote population but sterol itself must work for the improvement of the rate of emergence. The body size of the heat-treated planthoppers was smaller than that of the normal ones, even when cholesterol was given. The skin colour was yellowish or reddish, which is one of the characteristics of the heattreated insects. Some insects were dead halfway to ecdysis.

On the basis of Fig. 2, figures were collected for the growth curves of emergence. Firstly, the daily cumulative numbers of emerged adults were divided by the total number of adults that emerged by the 43rd day (Fig. 3). Metamorphosis of the 


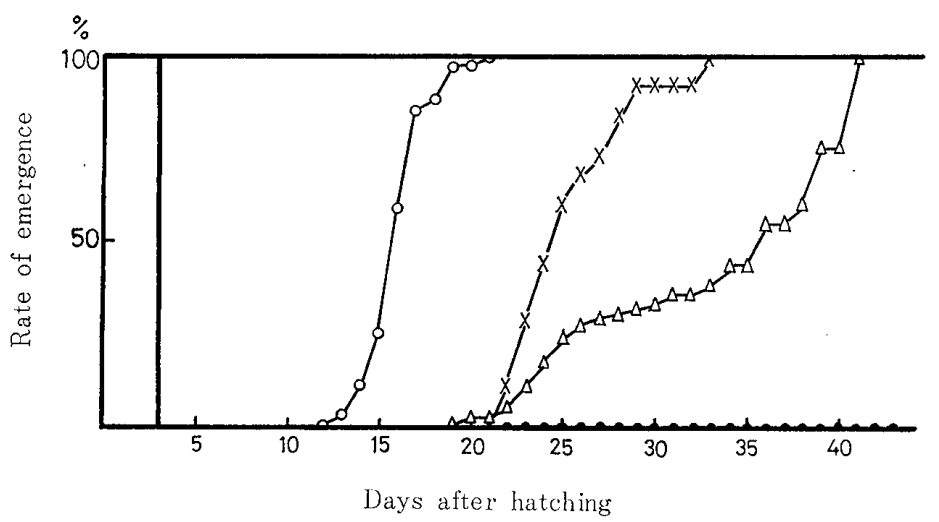

Fig. 4. Growth curve of adult emergence. The cumulative number of adults are divided by the alive insects each day. Figures are taken from Fig. 2.

Table 1. Application of Ecdysterone to the Heat-Treated 5th Instar Nymph

\begin{tabular}{|c|c|c|c|c|c|c|c|c|c|c|c|c|c|c|c|}
\hline \multirow{2}{*}{ Doses $(\mu \mathrm{g})$} & \multicolumn{5}{|c|}{ I } & \multicolumn{5}{|c|}{ II } & \multicolumn{5}{|c|}{ III } \\
\hline & a & $\mathrm{b}$ & $\mathrm{c}$ & d & $\mathrm{e}$ & $\mathrm{a}$ & $\mathrm{b}$ & $\mathrm{c}$ & d & e & a & $\mathrm{b}$ & c & d & $\mathrm{e}$ \\
\hline 1 & 34 & 10 & 10 & $5(2)$ & $9(0)$ & & & & & & & & & & \\
\hline $10^{-1}$ & 36 & 14 & 14 & $3(0)$ & $5(0)$ & 30 & 18 & 8 & $4(2)$ & 0 & & & & & \\
\hline $10^{-2}$ & 36 & 2 & 10 & $11(1)$ & $13(1)$ & 30 & 4 & 5 & $6(1)$ & $15(0)$ & & & & & \\
\hline $10^{-3}$ & & & & & & 30 & 5 & 6 & $8(3)$ & $11(1)$ & 25 & 3 & 12 & $6(1)$ & $4(0)$ \\
\hline $10^{-4}$ & & & & & & & & & & & 25 & 6 & 16 & $2(1)$ & $1(1)$ \\
\hline $10^{-5}$ & & & & & & & & & & & 25 & 8 & 15 & $1(1)$ & $1(1)$ \\
\hline control & 36 & 12 & 19 & $5(3)$ & 0 & 30 & 10 & 13 & $5(4)$ & $2(2)$ & 25 & 5 & 15 & $3(2)$ & $2(2)$ \\
\hline non-treatment & 36 & 20 & 15 & $1(0)$ & 0 & 30 & 13 & 11 & $2(2)$ & $4(4)$ & 25 & 11 & 12 & $2(2)$ & 0 \\
\hline
\end{tabular}

Insects were applied the 19th day after hatching. Cumulative number of insects are shown by 4 days after application. Parentheses show the number by 2 days.

a, number of insects examined; b, alive nymph; $c$, dead nymph; d, dead insect halfway to ecdysis; e, adult emerged.

normal insects occurred the 15th-16th day on average in this rearing, but the heattreated insects that ingested sterols mainly emerged the 22nd-24th day. Although the heat-treated insects required much time to emerge, the accomplishment of adult ecdysis mostly synchronized.

The daily cumulative numbers of emerged adults were then divided by those of the surviving insects that consisted of the adults and surviving nymphs (Fig. 4). The slope of the curve of the insects ingesting cholesterol is similar to that of the normal insects; these two curves are parallel on the whole. On the other hand, the slope of the curve of $\beta$-sitosterol is different from that of the normal insects. This gentler slope indicates that $\beta$-sitosterol did not fully recover the adverse effect of the heat treatment.

\section{Application of ecdysterone to the heat-treated 5th-instar nymphs}

Ecdysterone was applied to the heat-treated 5th-instar nymphs. The insects were divided into the following four groups after the application; "alive nymph", 
"dead nymph", "dead insect halfway to ecdysis" (e.g. the insects that shed half of the old cuticle or that tried to shed it), and "emerged adult". The insects that could not stand on their legs were included in the "dead nymph".

In Table 1, the cumulative numbers of four groups for 4 days after application are shown. The numbers in the parentheses are those for 2 days. Adults largely emerged or ecdysed at a dose of $10^{-2} \mu \mathrm{g}$. They tended to cease to moult at both higher and lower doses than $10^{-2} \mu \mathrm{g}$. This shows that there is an effective dose of ecdysterone near $10^{-2} \mu \mathrm{g}$ on the adult moult of the heat-treated 5th-instar nymphs. Adult ecdyses largely occurred in the 3rd or 4th day after application, because for 2 days only a small number of insects emerged or ecdysed.

\section{DISGUSSION}

A certain number of $L$. striatellus that received the heat treatment at the earliest stage of the nymph can grow up to the 5th-instar stage, but some were dead or remained in the 5th-instar stage (NodA and SaIto, 1979). Fig. 2 also shows that the heat-treated insects were mainly dead during adult ecdysis. The impact of the 3-day high temperature against the youngest nymphs reveals the deleterious effect on the very last stage of the nymphs. Sterol analyses show that the yeastlike symbiotes provide $L$. striatellus with 24-methylenecholesterol (NodA et al., 1979). Since the number of the yeastlike symbiotes in the heat-treated insects are greatly reduced, the amount of 24-methylenecholesterol is small and the cholesterol concentration is low. When cholesterol was administered to the heat-treated insects, 37.1\% emerged (Fig. 2). Cholesterol with Tween 85 also improved the adult ecdysis from $6.7 \%$ to $61.6 \%$ (Fig. 1). As far as the adult ecdysis is concerned, the deleterious effect of the heat treatment is mainly due to the lower concentration of cholesterol.

The microscopical observations of some heat-treated 5th-instar nymphs show that the deposition of adult cuticle does not normally occurred (Noda and SaIto, 1979). However, the endogeneous ecdysone must work, because some insects deposit a new cuticle and some adults emerge. The application of the exogeneous ecdysone (ecdysterone) stimulated the heat-treated 5th-instar nymphs to moult. In regard to the adult moult of the heat-treated insects, the application of ecdysterone has an effect similar to the administration of cholesterol. Since cholesterol is known as the precursor of ecdysones, the shortage of cholesterol might cause the insufficient ecdysone synthesis.

L. striatellus obtains $\beta$-sitosterol from the rice plant (NoDA et al., 1979). $\beta$ Sitosterol was less effective than cholesterol in promoting the heat-treated insects to emerge (Fig. 4). This seems to be partly due to the fact that the conversion of $\beta$ sitosterol into cholesterol requires several steps as shown in Manduca sexta, Tribolium confusum (Svoboda et al., 1975), and Bombxy mori (Morisaki et al., 1972). $\beta$-Sitosterol from the rice plant may play a minor part as the cholesterol source of this planthopper. 24-Methylenecholesterol from the yeastlike symbiotes seems to play an important role in the development of $L$. striatellus.

\section{AGKNOWLEDGEMENT}

The authors wish to express their thanks to Dr. S. NASU of the National Institute of Agricultural 
Science and Drs. O. Yamashita and H. KAI of the Sericultural Laboratory of Nagoya University for their helpful suggestions.

\section{REFERENGES}

Morisaki, M., H. Ohtaka, M. Okabayashi and N. Inekawa (1972) Fucosterol-24, 28-epoxide, as a probable intermediate in the conversion of $\beta$-sitosterol to cholesterol in the silkworm. J.C.S. Chem. Comm. 1275-1276.

NASU, S. (1963) Studies on some leafhoppers and planthoppers which transmit virus disease of rice plant in Japan. Bull. Kyushu agr. Expt. Stn. $8:$ 153-349 (in Japanese with an English summary).

NodA, H. (1977) Histological and histochemical observation of intracellular yeastlike symbiotes in the fat body of the smaller brown planthopper, Laodelphax striatellus (Homoptera: Delphacidae). Appl. Ent. Zool. 12 : 134-141.

Noda, H. and T. Saito (1979) Effects of high temperature on the development of Laodelphax striatellus (Homoptera:Delphacidae) and on its intracellular yeastlike symbiotes. Appl. Ent. Zool. 14 : 64-75.

Noda, H., K. Wada and T. Saito (1979) Sterols in Laodelphax striatellus with special reference to the intracellular yeastlike symbiotes as a sterol source. J. Insect Physiol. 25 : 443-447.

Svoboda, J. A., J. N. Kaplanis, W. E. Robbins and M. J. Thompson (1975) Recent developments in insect steroid metabolism. Ann. Rev. Ent. $20: 205-220$. 